\title{
College Students' Suicide Psychological Analysis and Crisis Intervention
}

\author{
Xiaoyan $\mathrm{Li}^{1, \mathrm{a}}$, Hailun $\mathrm{Du}{ }^{2, \mathrm{~b}}$ \\ ${ }^{1}$ Ideological and Political Theories Teaching Research Departments,Xi'an Technological University \\ Xi'an,710032,China \\ ${ }^{2}$ Ideological and Political Theories Teaching Research Departments,Xi'an Technological University \\ Xi'an, 710032,China \\ aemail:397366628@qq.com, bemail:40309581@qq.com
}

Keywords: College Students; Suicide; Prevention; Precaution

\begin{abstract}
College students are one of the group of the general population, the incidence of psychological problems as the same as general population. However, the college students are immature in mentality, they are lacking in social experience in education, employment, interpersonal relationships, economic conditions, and so on. They will met many kinds of pressure,and that will give them huge challenges of psychological adaptability. So it is leading to psychological setbacks,and making a suicide phenomenon easily. Finally college students will become the people at high risk of suicide. This paper analyzes the main reasons of college students' suicide, and puts forward how to prevent suicide and the ways of precaution for college students.
\end{abstract}

College students are one of the group of general population, the incidence of psychological problems as the same as the general population.In addition to the general reasons,there are two important reasons,one is after the tense university entrance exam,the college students have some legacy psychological problems,another one is the one-child too simple growth environment, and combined with their own physical and mental immaturity, they must to face enormous challenges in psychological adaptability .These psychological characteristics to make them in real life are more likely to produce all kinds of psychological problems, So it is leading to psychological setbacks,and making a suicide phenomenon easily. This paper analyzes the main reasons of college students' suicide the people at high risk of suicide.Through the analysis of college students suicide reason, and the college students suicide case,This article propose how to prevent the happening of the university students' suicide phenomenon is an important task in daily student work [1].

\section{The Main Reason for the College Students' Suicide}

After investigation of many college students' suicide in the Universities of xi'an, the main causes of suicide we thought that were:

\section{[1]Some of the lovelorn university students have suicide idea}

This research adopts the questionnaire to test some lovelorn university student, discovers most of them have suicide idea , partly have stronger idea. it's also one of the important factors that induce the college students' mental issue. Contemporary college students is full of romantic fantasy, but because of the emotion is not fully mature, at the time of emotion, rational control and self-control is very weak. For the lovelorn, contemporary college students often can produce embarrassment, shame, lost, sad, lonely, despair and a series of negative emotional reactions, make their body and mind are a lot of damage, formation of a severe emotional crisis. If not timely comfort or transfer, then easy leads to the formation of a lovelorn suicide, self-injury, revenge or depression. Compared with the students born in the 1970s, our country college students born after 80 s easy to fall in love, also easy to brokenhearted, the only-child born after the 80s inner loneliness. 


\section{[2]Some students who did not playing better in college entrance exam produce hostility,even have suicidal thoughts}

After the college entrance examination ,candidates are under tremendous psychological pressure, after the test ,the pressure is suddenly released completely, is easy to form a huge psychological gap, especially the exams is not ideal, for admission to the school, professional is not satisfied with candidates, after entering university will generate resentment, this part of the students' psychological problems, the most easily individual may even come up to the idea of suicide [2].

\section{[3]Over relaxation lead to some pressure on students learning}

Because of over relaxation state, some of the students have heavy mental pressure. Some students fully indulge in the so-called relaxation state when they went into the university, some students addicted to the Internet game, some students drinking, some students day and night to see a disc and so on, tend to form in psychological emptiness, numbness of the mental state, lead to the normal state of mind are destroyed. After one or two semesters, this part of the students failed the exam results will be more than, lead to leave after the downgrade, and there will be more psychological problems. Some of them even lose hope, and can't to confront his parents,then they have suicide idea.

[4]Vulnerable students will produce suicide idea because of the difficulties in domestic economy

Some students because of the difficulties in domestic economy, they can't correctly understand the economic relationship between poverty and mental poverty, often formed by cash-strapped serious inferiority mentality, so can't go shopping together with classmates, eat together, at the same time, strong sense of self-esteem and consider others care about take care of their compassion, sympathy, after a long time can produce anxiety, depression. If not timely adjust, psychologically vulnerable students will produce the idea of suicide.

So some psychological experts said that college students are often "blowout" period of students' psychological problem [3].

\section{The Remedial Measures to Prevent Students from Suicide}

If only in the current situation, we can take remedial measures are:

\section{[1]Try our best to understand each grade students' main troubles that they are facing}

Different grade students would encountered different problems . For example, one of the main specific problem is: adapt to living environment, the dormitory relationships; To the school and the university of professional identity, learning method to adapt; Economic problems, self-reliance, self awareness and acceptance. Sophomore is self understanding and acceptance, love, study, interpersonal relationship. Junior is looking for a problem, is the future direction of problem (one's deceased father grind? Work? Go abroad? , textbook learning, love. Senior year is relative to the future direction of various practical preparation (around one's deceased father grind preparation work, looking for a job to prepare a resume and looking for information, to go abroad to a foreign language, etc.), self-awareness and positioning, essay writing, etc. Living environment to adapt and deal with the dormitory relationship this kind of problem, because is very specific so well understood, but to a lot of problems caused by puberty has rarely cause the attention of parents and teachers. Such as inferiority, searching for the meaning of life and self-identity (goals), social tensions, perfectionism and emotional volatility, etc. To growth of students caused by all kinds of problem is particularly acute. In receiving counseling of college students, because of inferiority affects interpersonal and learning students accounted for more than $50 \%$ at least. Self-awareness and the meaning of life to find, for example, looks very empty phenomenon, but in the growth of a young man was occupied very big position, is a current young students can adapt to college life and can adapt to the society is an important issue in the future. A lot of young students in the process of self-awareness and looking for the meaning of life is full of struggle, these phenomena are parents and teachers should understand and support. 
[2]Put the life education into the construction of campus culture, and put some meaning of life and become some psychology courses as required courses that are helpful to promote students' mental health

Suicide prevention has been found that most of the time, young people commit suicide is not because he wanted to die, but because he didn't know why "alive" and "how to live," such a question on the outlook on life and values is very elusive problem, but this problem has not been generated when the solution does not value it will pose a real threat to people's life.

In recent years, colleges and universities set up the college students' mental health, interpersonal psychology, the interpersonal relationship training, the basic psychology, psychology of elective course. By teaching the course content, found some experience on the classroom activities, communication activities to help improve the students' psychological health level, to promote students' comprehension of the meaning of life, promoting students to strengthen self awareness, self growth had a significant effect. In addition, in terms of suicide prevention, psychology of management, stress management, emotional setbacks to deal with, problem solving, life education and puberty psychological law of development knowledge is very important.

\section{[3] College students' parents must contact with schools actively}

We usually found in the psychological consultation, many parents think they put the child support tasks completed after college, adult children, he development of which is decided by himself [4]. Some parents are busy working, only ask the child's life takes to the child. Parents give children return authenticity. Only when their children really wrong didn't attention parents. School must let parents to emphasis long-term on their children education .This for college students and cooperate with the school, the parents, it is not only more efficient but also more safety. In addition, it also help parents and children to learn more and understand, helps the family harmony with parents and children grow up together.

In the first day when new students entrance, in we can group parents listen to lectures. Let parents understand after the new students entrance,they maybe encounter some problems, as well as mental health and health care especially discern basic knowledge of psychological disease, etc. In addition, to inform parents can provide what kind of help and support to all students, encourage parents and children often contact the counselor, to understand their children in school.

\section{We Must Find Signs before Suicide Timely, and Intervention Effectively}

Research has shown that $60 \%-80 \%$ of all suicides in front of the suicide mentioned are directly or indirectly, want to die. One's suicide decision before there will be a lot of struggle, so there are signs of suicide. Suicide as long as found timely before the symptom can largely save the life of students. In order to do this, the school should enhance to counseling professionals training, establish and perfect the system of school psychological crisis early warning and intervention, the psychological test in screening the susceptible students to give more attention, keep in touch with all the departments shall be responsible for the students of the teacher, make this part of the teacher is basic flair for suicide. Not only that, but in school teachers and employees (including administrative departments at all levels of staff, such as dormitory, canteen management, cleaning personnel, the supermarket staff, etc.) in the training of mental hygiene popular science knowledge, including the most basic problems of psychological identification method and the basic knowledge of self psychological care and so on. Doing this can help prevent students suicide phenomenon, but also help teachers and staff's own mental health and personal growth.

\section{[1]We must understand the signs better before suicide [5]}

When some students appear the following warning signs,we must be closely monitored, in case of malignant events happened. such as: some students attempted to suicide before or home relatives and friends have committed suicide; Said that want to commit suicide; Send your precious things to people; And suicide to collect relevant information and discuss with people; Reveals the despair, helpless and anger for yourself or the world; Will die or depression as conversation, writing, and reading content or 
the theme of the works of art; Discuss their existing tools of suicide; Methodically arrange affairs; Or just say I wish I was dead, I don't want to live anymore; Or indirectly said similar to now no one can help got me, I can't stand it anymore, etc.

\section{[2]When someone found that suicidal students, immediate crisis intervention}

If a people want to Suicide,the main emotional experience is helpless, so in the concrete help suicidal student, discoverer to do is:

a Not to make any judgment to listen patiently. No critical listening not only can help another person completely express their inner pain, but also can let another person to experience deep warm and accompany, care, acceptance.

b To persuade the students in the process, must avoid to activate the psychological inversion of the parties, and students discuss how why want to commit suicide, and going to commit suicide rather than simply to ask students to give up committing suicide.

c To know what students met what kind of problems. College students due to lack of the ability to solve the problem, in a desperate, they think they will often take suicide as a way of solving the problem. So, understand the cause of students suicide, to conduct the students to the discussion of the problem and solve, it helps to reduce the students suicide.

d To understand whether the students have committed suicide, the evaluation of the student suicide risk has a very important role.

e To quickly mobilize resources around such as counselors, roommates and classmates to accompany the students arrived until parents and professionals.

\section{[3]For the upcoming suicide plan, students should grasp the discretion, be calm}

When someone want to suicide, or even suicidal behavior, we ought to be extra careful, rescue behavior must be appropriate. Found that students who want to commit suicide, must first respect, accept him, with understanding, care about the tone of the tell him: you have the right to commit suicide, suicide is a way to solve the problem; Then can say many people have experienced suicidal thoughts, make the parties by comparing with others feel they are not necessarily the most unlucky person in the world; Suicide is a when people meet with difficulties have not found a solution of an idea, emphasized that suicide is not purpose but a means to get rid of the pain of the parties; According to the emotional reaction of the parties can ask you meet what difficulty step by step all the painful don't want to live with you? Give him to provide psychological support, through the short communication found that social support system of the parties, to help it develop constructive and operational plan, encourage the try again; When the parties to calm down and discuss the consequences of suicide, in the wake of reason in the process of events of do a comb, maybe he will be from one village.

In a word, college students suicide prevention in colleges and universities is a systematic project. If our schools, parents, teachers and society to a highly social sense of responsibility to do, not only can effectively reduce the suicide rate of college students, but also for the students to create a very suitable for the healthy growth of the environment, and this kind of school environment, and will contribute to the harmonious development of society as a whole.

\section{References}

[1]Zhaohui. Liu, The college students' abnormal psychology guidance and adjustment that love , Journal of He Nan Radio and Television University, vol. 4,2007,20-22

[2]After test on mental adjustment, Health Network 2007-06-19, 39

[3]Mei.Yang, suicide prevention: to help young people know themselves to find the meaning of life, the China Youth Daily, 2007-09-23

[4] Four steps to walk for the parents of new students, 2006-9-22, http://www.edu201.com

[5]Sheng Li and Qiuyun Lv, (translate) the psychological consultation and treatment series: crisis intervention and trauma treatment ,China light industry press, September 2004, 152-153 